\title{
Belt and Road Initiative, globalization and institutional changes: implications for firms in Asia
}

\author{
Jiatao $\mathrm{Li}^{1}$ (D) $\cdot$ Gongming Qian ${ }^{2} \cdot$ Kevin Zheng $\mathrm{Zhou}^{3} \cdot$ Jane $\mathrm{Lu}^{4} \cdot \mathrm{Bin} \mathrm{Liu}^{5}$
}

Accepted: 7 April 2021/Published online: 21 April 2021

(C) Springer Science+Business Media, LLC, part of Springer Nature 2021

\begin{abstract}
Research on Belt and Road Initiative (BRI) is rising but far from complete. This special issue (SI) aims to enhance our understanding of how firms in Asia and beyond strategically respond to the BRI and what new theories and investigations are needed to better elucidate this new environment. In this editorial, we present a brief description of BRI, a review of related studies in the international business (IB) domain, a summary of the articles included in the SI and their contributions to the study of BRI, and an agenda for future research. We suggest that more attention should be given to examination of organizational heterogeneity under the BRI theme. In particular, there exists a variety of players like the governments of the host countries, non-government institutions, firms with different ownership structures, managers with different backgrounds, and their idiosyncratic characteristics should be incorporated in BRI studies. Moreover, future studies should find fine-grained ways to theorize and operationalize the policy effects of BRI. We call for further investigation of the consequences of BRI, including but not limiting to different aspects of IB activities, innovation, entrepreneurship, and corporate social responsibility.
\end{abstract}

Keywords Belt and road initiative $\cdot$ Asian and Pacific firms $\cdot$ Heterogeneity $\cdot$ Institutional context $\cdot$ Strategies

\footnotetext{
Jiatao Li

mnjtli@ust.hk

Gongming Qian

qiangm@sustech.edu.cn

Kevin Zheng Zhou

kevinz@hku.hk

Jane $\mathrm{Lu}$

jane.lu@cityu.edu.hk

Bin Liu

binliu@xmu.edu.cn
}

Extended author information available on the last page of the article 


\section{Introduction}

While the world has seen a steep rise of protectionism and anti-globalization sentiments (Prashantham et al., 2018), Belt and Road Initiative (BRI) is perceived as a new hope for outward-oriented economies, multinational enterprises (MNEs), small-to-medium sized enterprises (SMEs), and a variety of other stakeholders (Li et al., 2019; Li et al., 2021). Unveiled by President Xi Jinping during his state visit to Kazakhstan and Indonesia in 2013, BRI is designed to promote the infrastructure and trade along the land- and sea-based routes, which should inject new economic momentum under the current sentiments of rising deglobalization and protectionism (Buckley, 2020; Du \& Zhang, 2018; Li et al., 2019).

Though still at a young age, BRI has attracted growing research attention. While earlier literature has descriptively emphasized the motivation of the initiative and its risks and uncertainties from a political perspective (Gurin et al., 2015; Huang, 2016), more recent studies have started to recognize BRI's influences on business entities. For instance, Du and Zhang (2018) show that China's outward foreign direct investments (OFDIs) increase significantly along the BRI routes after the initiation of BRI. Li et al. (2019) corroborate that BRI-related subsidies incentivize the exporting toward BRI markets, while cultural friction and ethnicity differences of the owners create complications in capitalizing the policy benefits.

However, our understanding of this magnificent plan is still far from complete. First, organizations do not respond homogeneously to the BRI (Li et al., 2019; Li et al., 2021), thus calling for more investigations of organizational heterogeneities in respect of their responses. This knowledge of organizational heterogeneities is quite important for policymakers to fine-tune the policy with respect to different groups of players. For instance, China's state-owned enterprises (SOEs) are, by default, key players in the BRI but we do not know whether such policy design is effective for the achievement of policy or organizational objectives ( $\mathrm{Li}$ et al., 2019; Li et al., 2021). Second, BRI can be treated as either a policy incentive or a unique institutional context, yet the research attention is primarily on the former. In fact, BRI presents an ideal opportunity to examine the patterns of organizational coevolution with, and adaptation to, dramatic institutional changes, which have been called by proponents of institution-based theory (Lundan \& Li, 2019; North, 1999; Peng et al., 2008; Peng et al., 2018; Scott, 2013; Tang et al., 2021). Third, the BRI is likely to affect multiple aspects of an organization, yet prior studies tend to focus on its implications for the international business (IB) aspects of an organization (Li et al., 2019). Thus, it is necessary to identify other affected aspects to sketch more complete theoretical contours of BRI.

Based on the above identified gaps, we issued a call for papers at Asia Pacific Journal of Management (APJM). Entitled "Belt and Road Initiative, Globalization and Institutional Changes: Implications for Firms in Asia", this APJM special issue (SI) intends to uncover the de-globalization challenges for, and strategic responses of, firms in Asia. Such exploration is especially needed given that the US and China seem to have changed their positions on global economies, manifested by the US's pursuit of protectionism versus China's initiation of BRI and globalization. Encouragingly, the SI generated broad interest among scholars and we received 28 initial submissions. After the first round of review, 10 papers were offered the opportunity to revise and resubmit 
$(\mathrm{R} \& \mathrm{R})$, and all of them were invited for presentation at the paper development workshop hosted by the School of Management at Xiamen University on December 17-18, 2019, for exchange of ideas and discussions on how to improve the quality of the manuscripts to ensure a thematic coherence. After several rounds of reviews, six papers were finally accepted to be included in the SI.

To provide a more comprehensive view on BRI, we have also included a conceptual paper assessing the BRI as a narrative, and exploring implications for institutional change and international firm strategy. Specifically, this study has argued that BRI has to pass the narrative virality test to become the new force of institutional changes. The paper was accepted after a regular double-blind review process at $A P J M$, managed by APJM consulting editor Professor Mike Peng. Combined, those seven articles should provide new insights into the influences of BRI and outline future directions of BRI studies.

In the next three sections, we first highlight the key elements of BRI in tandem with a brief literature review of BRI, summarize the specific contributions of the articles in this SI, and introduce an agenda for future BRI research.

\section{Key elements of BRI}

Although China has been one of the fastest-growing economies, the Chinese government has had serious concerns over its under-developed Western regions and risks of production overcapacity (Du \& Zhang, 2018; Li et al., 2019). Deepening cooperation with economies in Asia, Middle East, and Europe could be a strategy to address these issues because most of those neighboring markets are still emerging and China has long trading connections of silk, china, etc. with them since its ancient time in the Han dynasty (around 202 B.C. to 114 B.C.). To sustain China's economic development while taking advantage of the historical ties (Swaine, 2015), BRI was unveiled by the President of China during his state visit in Kazakhstan and Indonesia in September and October 2013 respectively (Li et al., 2019).

As one of the most significant international programs in the twenty-first century (Buckley, 2020; Li et al., 2021), BRI intends to build a prosperous Eurasia economic community via land- and sea-based connections (Du \& Zhang, 2018; Li et al., 2019). Specifically, the land-based corridors connect East Asia, Central Asia, Middle East, and Europe by the highway and railway links, whereas the sea-based connections are manifest in the sea-borne traffic among China, Southeast Asia, and Africa (Belt and Road Portal, 2017), indicating the pioneering function of governmental cooperation and infrastructure development (Huang, 2016; Li et al., 2019). Claimed as an allinclusive project (Belt and Road Portal, 2017), more than 140 countries have now (i.e., by the end of January in 2021) joined BRI by signing collaboration agreements or memorandum of understanding (Belt and Road Portal, 2021). The figure below, from The World Bank report, illustrates the geographic coverage of BRI Fig. 1.

\section{Literature review of BRI studies}

Though still at an initial stage, BRI has attracted rising research attention. Most early attention came from media reports and policy studies focusing on the pros and cons of BRI perceived as a reflection of the Chinese government's political interests (Yan et al., 


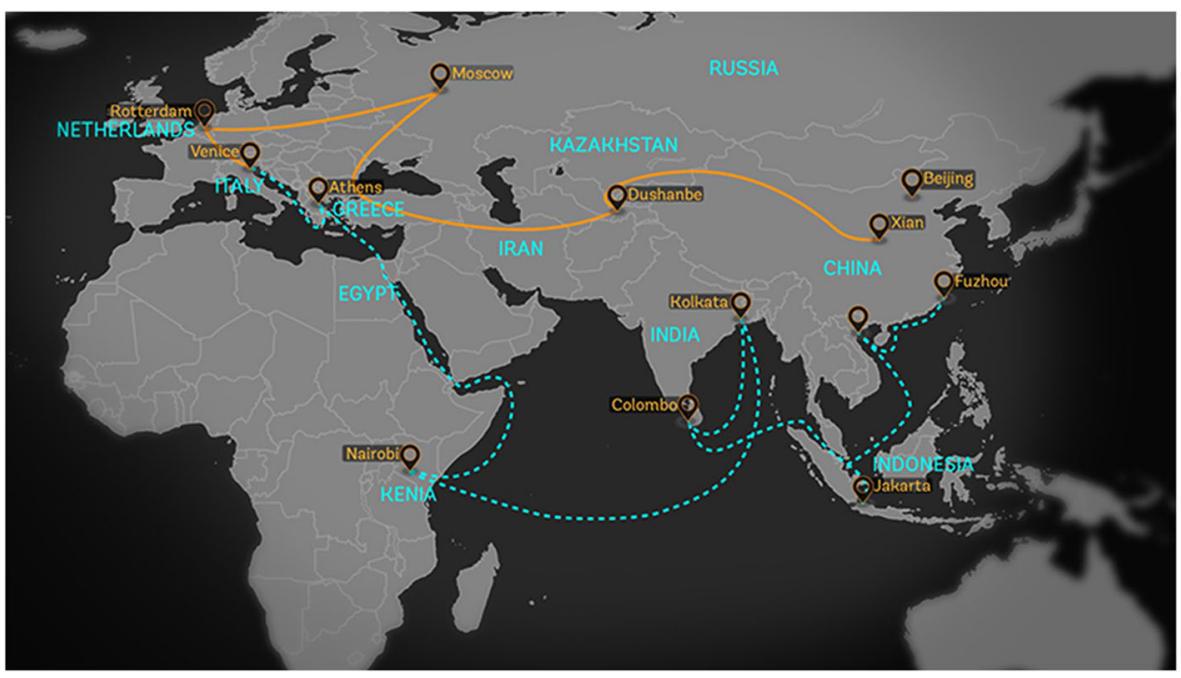

Fig. 1 Geographic coverage of BRI. Source: https:/www.worldbank.org/en/topic/regional-integration/brief/ belt-and-road-initiative

2018). On the one hand, some studies recognize the profound potentials of BRI (Anderlini, 2015). For instance, Huang (2016) postulates that BRI makes BRI regions new vibrant economic pillars under efficient cross-border cooperation. Cheng (2016) argues that China seems qualified to ensure a policy framework toward mutual benefits. On the other hand, there are heightened concerns on political instability, religious conflicts, corruption, wars and terrorism, and other risks along the planned routes (Gurin et al., 2015; Zhang et al., 2020). Buckley (2020) posits that black swan events like the COVID-19 might bring in additional uncertainties to the success of BRI.

Recent studies have started to provide some evidence about whether BRI generates positive effects. Zhai (2018) predicts that BRI would bring sizeable benefits in terms of welfare and trade even under a conservative assumption of total investment in a simulation. Comparing merger and acquisition (M\&A) deals before and after BRI, Du and Zhang (2018) find that China's OFDIs rise significantly along the Belt and Road while SOEs indeed play a key role in infrastructure industries as claimed in the blueprint. Taking a micro-foundation standpoint, Li et al. (2019) confirm that the exports by Chinese SMEs have increased significantly with the financial subsidies of BRI despite of cultural friction and ethnicity differences. Similarly, Quer (2021) unveils the positive effects of BRI in the tourism industry as Chinese tourists seem to prefer the countries on the BRI list.

However, many aspects of BRI remain unknown. First, different organizations may behave differently under the BRI. For instance, SOEs are assumed to be the key pioneers in the BRI, but they may possess contradictory considerations and interests (Li et al., 2019), same for family firms and NGOs. One obvious yet omitted heterogeneity could emerge from the ownership structure such that firms with different levels of state ownership may present different levels of enthusiasms toward participation in the BRI projects. This knowledge is important for policymakers to fine-tune the policies for different groups of players. 
Second, prior research has primarily viewed BRI as a policy incentive, but BRI is also a unique institutional context. Most studies have emphasized the policy effects of BRI by either comparing the relative changes before and after the launch of BRI or examining the effects of policy-related incentives (e.g., Du \& Zhang, 2018; Li et al., 2019). Yet, BRI can generate fundamental changes in institutional conditions rather than a mere policy incentive. We propose that BRI also presents a good opportunity to examine the patterns of organizational co-evolution with, and adaptation to, dramatic institutional changes. That is, organizational behaviors are largely influenced by the institutional environment in which the firms are embedded (Li \& Harrison, 2008; Li \& Yue, 2008; Young et al., 2014). BRI also introduces a new platform of international cooperation among emerging economies. Given that most contemporary IB theories have emerged from IB activities among developed economies and/or between developed and emerging economies (Qian, 2000), they may not hold under the BRI theme of cooperation among emerging economies and the identification of different patterns in varying contexts is important for IB theory development.

Third, prior studies have mainly focused on IB activities (e.g., OFDIs and exporting), given that the main goal of BRI is to promote bilateral and multilateral trade and investment (Buckley, 2020; Du \& Zhang, 2018). However, BRI can generate influences on a variety of organizational dimensions such as corporate social responsibility (CSR), innovation, human resource management, and others. Furthermore, IB activity per se also includes the scale, scope, and speed of FDI, entry modes such as joint ventures, and so on ( $\mathrm{Li}$ et al., 2019). It is therefore necessary to examine various dimensions of impacts to generate a more complete theoretical contour of BRI.

\section{Summary of the articles included in the SI}

Filling in those gaps is both theoretically and practically urgent for Asian firms, which play important roles under the BRI theme. The seven articles included in this SI have addressed those issues of BRI research in their distinctive ways ${ }^{1}$ Table 1.

Casas-Klett and Li's (2021) article, entitled as "Assessing the Belt and Road Initiative as a narrative: Implications for institutional change and international firm strategy," introduces a new theoretical perspective to examination of the feasibility of BRI. This conceptual paper proposes that the success of BRI depends on its narrative virality in contention with competing narratives of deglobalization. They introduce four testable propositions, depicting the preconditions for the BRI narrative of globalization to go viral. Specifically, BRI must realize a consistent set of meaningful and legitimate values for Chinese and host country stakeholders and invite their participation. Moreover, the initiative has to be open-ended and evolutionary while carrying institutions and rules that provide sustained benefits for all stakeholders. This article offers fresh insights on the determinants of the success of BRI.

Wang and Liu's (2021) study, entitled as "State equity and outward FDI under the theme of Belt and Road Initiative," emphasizes the organizational heterogeneities under the BRI context. Premised on the agency perspective of institutional theory, they show that Chinese listed firms with higher state equity present greater proactiveness in

\footnotetext{
${ }^{1}$ Particularly, we emphasize on their contributions to the SI theme of BRI albeit all of those studies have implitions for other domains as well.
} 


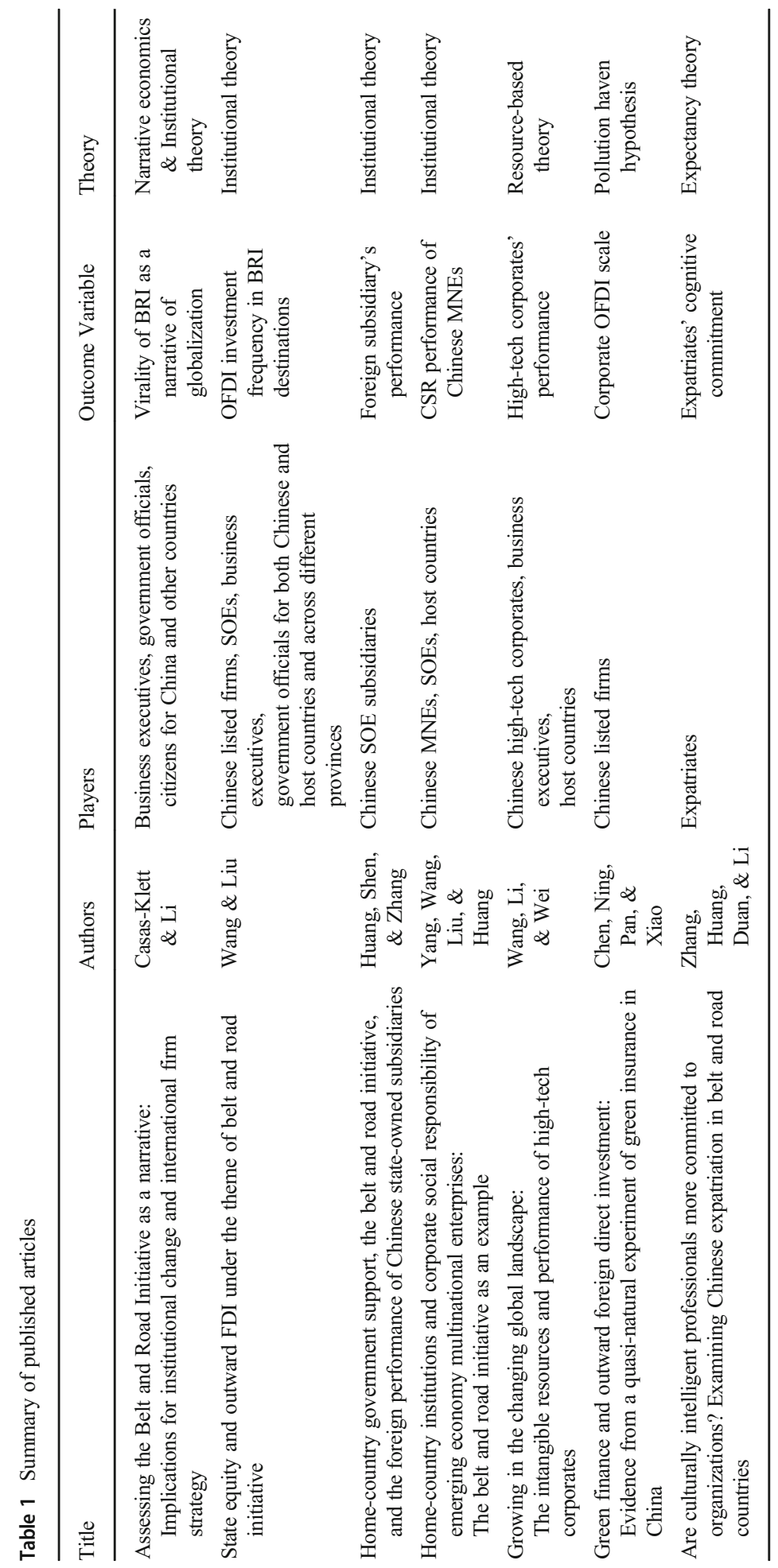




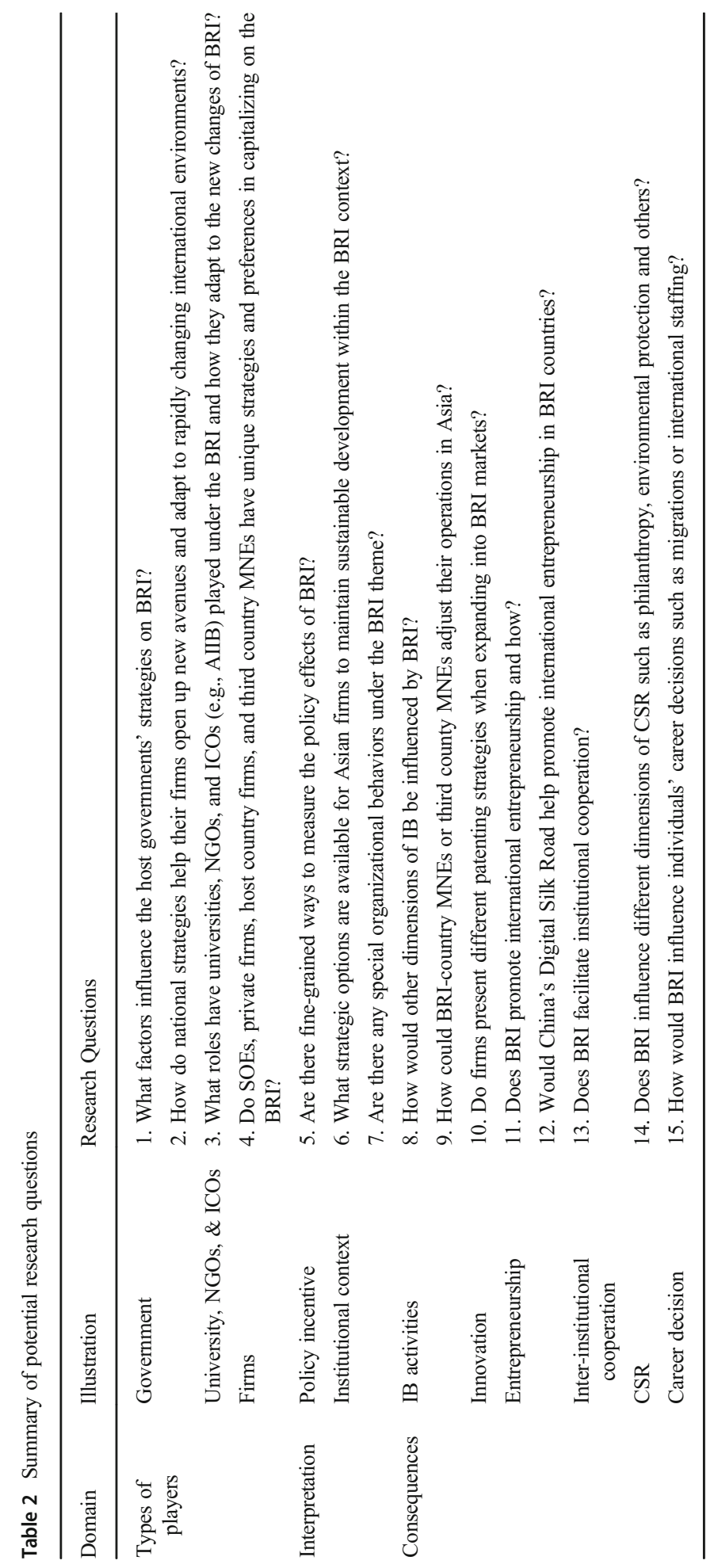


investing along the BRI routes with respect to the level of state equity. Moreover, both organizational (i.e., non-central government ownership and managers' foreign exposure) and institutional (i.e., organizational location and bilateral treaties between China and the focal BRI destination) contingencies further bring in complexities in BRI investment decisions. Their findings challenge the taken-for-granted assumption that SOEs spare no efforts in participating in BRI while explicating the underlying mechanisms.

In parallel, Huang, Shen, and Zhang's study (Huang et al., 2021), entitled as "Homecountry government support, the Belt and Road Initiative, and the foreign performance of Chinese state-owned subsidiaries," investigates the foreign performance of Chinese SOEs from a different perspective. Using a survey dataset, they identify the advantage of SOEs in capitalizing governmental support, improving their foreign subsidiaries' performance. Moreover, this advantage becomes weaker in BRI-participating countries whereas institutional difference further weakens this negative moderating effect of BRI destinations. In this sense, they theorize BRI as a special identification to capture their proposed heterogeneities of legitimacy concerns among different countries.

Yang et al. (2021) study, entitled as "Home-country institutions and corporate social responsibility of emerging economy multinational enterprises: The Belt and Road Initiative as an example", highlights the special institutional pressure of CSR faced by SOEs under the BRI theme. They find that the BRI can significantly improve the CSR performance of Chinese MNEs involved in this initiative, and such effects are stronger for SOEs and firms investing in the host countries with higher levels of institutional governance quality.

Chen et al. (Chen et al., 2021) link CSR policies with internationalization under the umbrella of CSR. In their manuscript entitled as "Green finance and outward foreign direct investment: Evidence from a quasi-natural experiment of green insurance in China", they postulate that China's green insurance pilot policies in 2007 would have a stronger impact on the OFDI of firms in regions with high marketization, but a weaker impact on OFDI if firms invest in BRI countries. At the kernel, they propose that foreign expansion into the BRI countries provides additional benefits for firms to offset the costs of green finance.

The BRI can also take effect in the research and development (R\&D) aspects. Wang et al.'s (2021) study, entitled as “Growing in the changing global landscape: The intangible resources and performance of high-tech corporates," supplements such research dearth. Using 223 listed Chinese high-tech corporations, they find that top managers' political ties weaken the negative effects of $R \& D$ intensity on the short-term performance. Meanwhile, the export environmental dynamism of the United States reduces, yet that of the BRI countries reinforces the moderating effects of political ties. As such, they highlight that BRI participation can reflect a special institutional condition that affects organizational strategies and performances.

Entitled as "Are culturally intelligent professionals more committed to organizations? Examining Chinese expatriation in Belt and Road Countries", the study by Zhang et al. (Zhang et al., 2021) treats BRI countries as a sampling context. They contextualize the study in the BRI context and propose that employees find more career opportunities and job flexibility among those BRI destinations. As such, this study inspires further examination on the individual-level differences under the BRI theme. 
While each of the manuscripts has introduced a distinctive perspective to understand the BRI, there are some implicit connections among them. First, firms can react heterogeneously under the BRI theme. While Casas-Klett and Li (2021) propose that international firm performance can co-vary with the virality of BRI narrative in different markets, Wang and Liu (2021) argue that ownership structure triggers idiosyncratic organizational internationalization under the BRI theme, same as Huang and her colleagues (Huang et al., 2021) do.

Second, all the articles in this SI have theorized BRI as a context rather than as a mere policy incentive. Except that Yang et al. (Yang et al., 2021) treat it as a policy incentive by directly comparing the CSR performance before and after BRI, all other papers in this SI have theorized BRI as a special institutional context. This context may bring in uncertain institutional influences depending on the BRI's virality from a narrative perspective (Casas-Klett \& Li, 2021). It can also be manifest in different degrees of political pressures for different firms from an agentic view of institutional theory (Wang \& Liu, 2021) or homogeneous CSR pressures from the structured view of institutional theory (Yang et al., 2021). It may be a further carrier of legitimacy favorability among BRI-participating countries (Huang et al., 2021; Wang et al., 2021), financial support (Chen et al., 2021) or more career opportunities (Zhang et al., 2021).

Third, several articles help extend the consequences of BRI. For example, Wang and Liu (2021) move the focus from OFDI scale to OFDI frequency. Yang et al. (Yang et al., 2021) focus on CSR behaviors, and Wang et al. (2021) on innovation activities. Zhang et al. (2021) further dig into micro-level aspects and argue that individuals' cognitive cultural intelligence has an inverted U-shaped relationship with organizational commitment among international professionals to Chinese cross-border BRI projects. Among the seven papers included in this special issue, one remains at a macro level (the narrative paper), five at an organizational level, and one at an individual level, all showing that BRI indeed affects multiple aspects of organizations.

\section{An agenda for future research}

While the articles in the SI have substantially advanced a theoretical understanding of BRI, there still remain many questions to be answered. We propose that future examination of BRI should systematically consider the types of players, interpretation of BRI, and dimensions of consequences.

First, there are distinctive types of players and each holds idiosyncratic interests under the BRI theme. One omitted group of players from prior research is the governments of host countries. The governments of the host countries possess salient regulatory discretions and heterogeneous attitudes on the BRI, which has been frequently overlooked in the extant studies. Under the current anti-globalization sentiments (Prashantham et al., 2018) and geopolitical struggles along the BRI routes (Li et al., 2019), different host countries might respond to BRI differently (Casas-Klett \& Li, 2021; Li et al., 2021). A closer examination of the roles of different levels of governments and their concerned interests could better direct organizational strategies under the BRI theme. For instance, different stances on the BRI are evidenced both among developed countries (e.g., USA versus Germany) and among states or provinces within a single country (e.g., State of Victoria of Australia had joined the BRI but was banned later by the Australian government); so it is promising to disentangle the 
antecedents of those differences. Moreover, governmental responses can take the form of idiosyncratic policies that influence how Asian firms would deal with the coexistence of globalization and de-globalization challenges ( $\mathrm{Lu}$ et al., 2018), which is particularly demanding in current historical moment. Heterogeneities of policies exist among home countries (e.g., China), host countries (e.g., BRI participating countries), and third countries (e.g., USA), which have practical implications for firms operating across multiple countries and theoretical implications for institutional polycentrism (Casas-Klett \& Li, 2021).

Another overlooked player is non-government institutes like universities and international cooperation organizations (ICOs), such as Asian Infrastructure Investment Bank (AIIB), and others, which may affect the cross-country cooperation. Although prior studies have highlighted that cultural friction and conflicts can be potent drags of BRI (Li et al., 2019), we do not know whether academic institutions can help alleviate the concerns. Similarly, limited studies have been found to examine whether and how ICOs like the AIIB adjust the lending policy based on either political or economic considerations, which would have effects on the development of BRI and organizational responses to BRI.

It is worthwhile to reiterate differences in business entities. While the articles included in this SI have pinpointed the special characteristics of SOEs under the BRI theme (Huang et al., 2021; Wang \& Liu, 2021; Yang et al., 2021), family-owned enterprises (FOEs) and NGOs may have distinctive utility functions. In addition to the equity differences, such distinctiveness can emerge from personal experiences or ideologies as well. That is, similar heterogeneities can be applied to individual levels as well, no matter whether they belong to a formal organization (e.g., SOE, FOE, NGO) or not. For example, it is yet known whether host country managers who have international experience in the West would show a welcoming gesture toward the BRI given that they may be educated with different logics of risk assessment or ideologies. Decision-makers' attitudes and experiences are important considerations to the establishments and successes of international cooperation under the policy theme. In a nutshell, studies of BRI should pay special attention to the characteristics of corresponding players.

Second, future studies should allow different interpretations of BRI. To capture the policy effects of BRI, we encourage the application of difference-in-difference (DID) method looking at before and after the year 2013 and development of fine-grained proxies to measure the effects of the BRI. For example, the quantity of BRI-related subsidies or loans can be potential candidates (e.g., Li et al., 2019). However, a key aim of this type of theorization is to identify any specialties of organizational behaviors under the BRI theme as compared to those previous findings under different contexts. As in the Strategic Management Journal, we find it particularly fruitful to replicate prior studies to the BRI context. As such, we can fully utilize BRI as a laboratory to examine the patterns of organizational co-evolution with, and adaptation to, dramatic institutional changes.

Third, the consequences of BRI need to be enriched. IB strategies are multidimensional, including the internationalization performance such as the scale, scope, and speed, direction of FDI as well as the entry mode such as joint venture, greenfield investment, and cross border acquisitions. However, few studies have examined whether the BRI generates different effects along multiple dimensions of IB activities. 
There are also insufficient attention on the IB activities among those BRI countries, which reflects whether BRI creates mutual economic prosperity. For instance, we are yet to know whether the imports and investments from BRI countries to China have increased substantially after the launch of the BRI.

There is also a paucity of investigations into organizational innovation and entrepreneurship under the BRI theme, which are key catalysts of developments among Asian firms (Liu \& Wang, 2020; Tian et al., 2021). While Wang et al. (2021) serve as a good starting point, a variety of innovation topics can be further explored. For example, future research could explore patenting strategies for firms that intend to expand market shares along the BRI routes given the generally weak regime of intellectual property protection in those countries. In parallel, it is worthy of investigating whether BRI has promoted entrepreneurship activities across the borders and whether China's Digital Silk Road policy and digital technology giants (e.g., Alibaba, Tencent, Huawei, etc.) can help promote new ways of international entrepreneurship along the routes.

Dimensions in those nonfinancial aspects are also promising venues for future exploration. In respect of non-government organizations, we do not have a good understanding of how BRI facilitates inter-institutional cooperation like cultural exchange programs though they are frequently reported in the media. While we have some evidence that Chinese MNEs substantially improve their CSR performance under the BRI theme (Yang et al., 2021), there is a clear need for more research to investigate different dimensions of CSR like philanthropy, environmental protection, and others. Echoing with the individual-level analyses we have advocated, individual career decisions such as whether they are more likely to migrate to another BRI country or take on international assignments are fruitful as they help enrich the understanding of BRI. In Table 2, we list potential questions for exploration in the future.

\section{Conclusion}

In this editorial and the accompanying SI articles, we aim to take a further step toward addressing the challenges in understanding how Asian firms and beyond strategically respond to the BRI and what new theories and evidence are needed to better explain this new institutional environment. We develop a framework to point out what have been examined and what have been overlooked in the BRI domain. An important aspect of the framework is to recognize the heterogeneity among the players, interpretation, and consequences of BRI. In doing so, we intend to set out a basis for future research agenda that has important implications for the sustainability of businesses in Asia and beyond, and for deeper, interdependent economic cooperation among BRI countries. We hope this special issue could inspire more explorations of BRI.

Acknowledgements We thank APJM Editor-in-chief Chi-Sum Wong and consulting editor Mike Peng for their support of the special issue, and the School of Management, Xiamen University for its excellent support in hosting the SI workshop in December 2019. We also thank the authors and reviewers for their contributions. The research is supported in part by the Research Grants Council of Hong Kong (HKUST\#16505817 and 16507219), National Natural Science Foundation of China (grant 71932007), and the Fundamental Research Funds for the Central Universities (No. 2072021126). 


\section{References}

Anderlini, J. (2015). China to become one of world's biggest overseas investors by 2020. Retrieved Oct 16, 2020 from Financial Times (North American Edition) https://www.ft.com/content/5136953a-1b3d-11e58201-cbdb03d71480.

Belt and Road Portal. (2021). List of countries that have signed cooperation documents with China on jointly build Belt and Road Initiative [in Chinese]. Retrieved Mar 15, 2021, from https://www.yidaiyilu.gov.cn/ xwZX/roll/77298.htm.

Belt and Road Portal. (2017). Combing the blueprint of the Belt and Road Initiative [in Chinese]. Retrieved Oct 16, 2020, from https://www.yidaiyilu.gov.cn/ztindex.htm.

Buckley, P. J. (2020). China's Belt and Road Initiative and the COVID-19 crisis. Journal of International Business Policy, 3(3), 311-314.

Casas-Klett, T., and Li, J. (2021). Assessing the Belt and Road Initiative as a narrative: Implications for institutional change and international firm strategy. Asia Pacific Journal of Management, https://doi.org/ 10.1007/s10490-021-09757-x.

Cheng, L. K. (2016). Three questions on China's "Belt and Road Initiative". China Economic Review, 40, 309-313.

Chen, Q., Ning, B., Pan, Y., \& Xiao, J. (2021). Green finance and outward foreign direct investment: evidence from a quasi-natural experiment of green insurance in China. Asia Pacific Journal of Management, https://doi.org/10.1007/s10490-020-09750-w.

Du, J., \& Zhang, Y. (2018). Does One Belt One Road initiative promote Chinese overseas direct investment?. China Economic Review, 47, 189-205.

Gurin, N., How, P. D. S., Jackson, S. A., \& Yu, P. N. (2015). How significant are the security and political risks and threats to China's grand westward strategy in Central Asia? University of Hong Kong Libraries.

Huang, Y. (2016). Understanding China's Belt \& Road Initiative: Motivation, framework and assessment. China Economic Review, 40, 314-321.

Huang, Y., Shen, L. \& Zhang, C. (2021). Home-country government support, the Belt and Road Initiative, and the foreign performance of Chinese state-owned subsidiaries. Asia Pacific Journal of Management, https://doi.org/10.1007/s10490-020-09743-9.

Li, J. \& Harrison, R. (2008). National culture and the composition and leadership structure of boards of directors. Corporate Governance: An International Review, 16 (5): 375-385.

Li, J. \& Yue, D.R. (2008). Market size, legal institutions, and international diversification strategies: Implications for the performance of multinational firms. Management International Review, 48 (6): 667-688.

Li, J., Liu, B., \& Qian, G. (2019). The Belt and Road Initiative, cultural friction and ethnicity: Their effects on the export performance of SMEs in China. Journal of World Business, 54(4), 350-359.

Li, J., Van Assche, A., Li, L., \& Qian, G. (2021). Foreign direct investment along the Belt and Road: A political economy perspective, Journal of International Business Studies, in press.

Liu, B., \& Wang, Q. (2020). Can certification help incumbent firms?. Asia Pacific Journal of Management, 37, 11061-1083.

Lu, J. W., Li, W., Wu, A., \& Huang, X. (2018). Political hazards and entry modes of Chinese investments in Africa. Asia Pacific Journal of Management, 35(1), 39-61.

Lundan, S. \& Li, J. (2019). Adjusting to and learning from institutional diversity: Toward a capability-building perspective. Journal of International Business Studies, 50(1), 36-47.

North, D. (1999). An introduction to institutions and institutional change. Institutions, Institutional Change and Economic Performance. Cambridge University Press.

Peng, M. W., Lebedev, S., Vlas, C. O., Wang, J. C., \& Shay, J. S. (2018). The growth of the firm in (and out of) emerging economies. Asia Pacific Journal of Management, 35(4), 829-857.

Peng, M. W., Wang, D. Y., \& Jiang, Y. (2008). An institution-based view of international business strategy: A focus on emerging economies. Journal of International Business Studies, 39(5), 920-936.

Prashantham, S., Eranova, M., \& Couper, C. (2018). Globalization, entrepreneurship and paradox thinking. Asia Pacific Journal of Management, 35(1), 1-9.

Qian, G. (2000). Performance of US FDI in different world regions. Asia Pacific Journal of Management, 17(1), 67-83.

Quer, D. (2021). Location decisions of Chinese firms in the global tourism industry: The role of prior international experience and diplomatic relations. Journal of Hospitality and Tourism Management, 46, 62-72. 
Scott, W. R. (2013). Institutions and organizations: Ideas, interests, and identities. Sage Publications.

Swaine, M. D. (2015). Chinese views and commentary on the 'One Belt, One Road' initiative. China Leadership Monitor, 47, 1-24.

Tang, R. W., Shu, C., \& Zhou, K. Z. (2021). State ownership of Chinese firms and their outward foreign direct investment: Political and economic contingencies. Asia Pacific Journal of Management, https://doi.org/ 10.1007/s10490-021-09756-y.

Tian, L., Yang, J. Y., \& Li, J. (2021). Does legal registration help or hurt? The effect of government corruption on resource acquisition by nascent ventures in an emerging economy. Asia Pacific Journal of Management, https://oi.org/10.1007/s10490-019-09673-1.

Wang, R., Li, YN. \& Wei, J. (2021). Growing in the changing global landscape: the intangible resources and performance of high-tech corporates. Asia Pacific Journal of Management, https://doi.org/10.1007/ s10490-020-09744-8.

Wang, Q., \& Liu, B. (2021). State equity and outward FDI under the theme of Belt and Road Initiative. Asia Pacific Journal of Management, https://doi.org/10.1007/s10490-020-09716-y.

Yan, Z. J., Zhu, J. C., Fan, D., \& Kalfadellis, P. (2018). An institutional work view toward the internationalization of emerging market firms. Journal of World Business, 53(5), 682-694.

Yang, N., Wang, J., Liu, X., \& Huang, L. (2021). Home-country institutions and corporate social responsibility of emerging economy multinational enterprises: The Belt and Road Initiative as an example. Asia Pacific Journal of Management, https://doi.org/10.1007/s10490-020-09740-y.

Young, M. N., Tsai, T., Wang, X., Liu, S., \& Ahlstrom, D. (2014). Strategy in emerging economies and the theory of the firm. Asia Pacific Journal of Management, 31(2), 331-354.

Zhai, F. (2018). China's Belt and Road Initiative: A preliminary quantitative assessment. Journal of Asian Economics, 55, 84-92.

Zhang, Y., Huang, L., Duan, Y., \& Li, Y. (2021). Are culturally intelligent professionals more committed to organizations? Examining Chinese expatriation in Belt \& Road Countries. Asia Pacific Journal of Management, https://oi.org/10.1007/s10490-020-09745-7.

Zhang, Y., Tsang, D., \& Fuschi, D. L. (2020). Chinese multinationals on the New Silk Route: Managing political risk by branding the nation. Thunderbird International Business Review, 62(3), 291-303.

Publisher's note Springer Nature remains neutral with regard to jurisdictional claims in published maps and institutional affiliations.

Jiatao (JT) Li (PhD, University of Texas at Dallas, USA) is Chair Professor of Management, Lee Quo Wei Professor of Business, Director of the Center for Business Strategy and Innovation, and Senior Fellow of the Institute for Advanced Study (IAS), Hong Kong University of Science and Technology. He is a Fellow of the AIB and an editor of the Journal of International Business Studies. His research interests are in the areas of global strategy, innovation, entrepreneurship, corporate governance, and digital economy.

Gongming Qian (PhD, Lancaster University, England) is full professor of the Department of Information Systems and Management Engineering at the Southern University of Science and Technology, Shenzhen, and former chair of the Department of Management at the Chinese University of Hong Kong. His research interests include the financial economics of multinational enterprises and foreign direct investment, international strategy, and entrepreneurship.

Kevin Zheng Zhou (PhD, Virginia Polytechnic Institute and State University, USA) is Chair of Strategy and International Business and Chung Hon-Dak Professor in Strategy and International Business at Faculty of Business and Economics, University of Hong Kong. His research interests include capabilities and innovation, trust and relational ties, and strategic issues in emerging economies.

Jane Lu (PhD, University of Western Ontario, Canada) is Chair Professor and Head of Department of Management, City University of Hong Kong. She is a Fellow of the AIB, a consulting editor of the Journal of International Business Studies and the President of Asia Academy of Management. Her current research centers on the intersection between organization theory and strategy with a focus on international strategy and non-market strategy of emerging market firms. 
Bin Liu ( $\mathrm{PhD}$, Chinese University of Hong Kong) is an Assistant Professor at Xiamen University. His research interests are international business, corporate governance, and family business with a focus on emerging economies. He is one of the leading pioneers in investigating the Belt and Road Initiative in the international business domain. He has published research articles in journals as Asia Pacific Journal of Management, Journal of World Business, Multinational Business Review, Nankai Business Review International, and etc.

\section{Affiliations}

\section{Jiatao $\mathrm{Li}^{1} \cdot$ Gongming Qian ${ }^{2} \cdot$ Kevin Zheng Zhou ${ }^{3} \cdot$ Jane $\mathrm{Lu}^{4} \cdot \mathrm{Bin} \mathrm{Liu}^{5}$}

1 Department of Management, Hong Kong University of Science and Technology, Clear Water Bay, Hong Kong

2 School of Business, Southern University of Science and Technology, Shenzhen, China

3 Faculty of Business and Economics, University of Hong Kong, Pokfulam, Hong Kong

4 Department of Management, City University of Hong Kong, Kowloon, Hong Kong SAR

5 Department of Business Management, Xiamen University, Xiamen, China 